\title{
Cytological screening and management of abnormalities in prevention of cervical cancer: an overview with stochastic modelling
}

\author{
C Sherlaw-Johnson, S Gallivan, D Jenkins, $M$ H Jones
}

\begin{abstract}
Aims-To develop a mathematical model of the histological changes of precancer and the development of invasive cancer and how these are related to cytological findings. To use this to investigate the effects on incidence of cervical cancer, number of smear tests and colposcopies, of different schedules for cervical screening, and the clinical management policies for dyskaryosis.
\end{abstract}

Methods-A stochastic model was developed relating the available data on tissue progression to the cytological findings. Two strategies, $A$ and $B$, were compared: under $A$, women with any abnormal smear receive immediate colposcopy and treatment; under $B$, women with mild or borderline dyskaryosis have repeated smears at six monthly intervals with colposcopy only for persistent abnormalities. Results-The model predicted an incidence of invasive cervical cancer in an unscreened population of women aged over 18 years of 5.9 per 10000 per year. With $70 \%$ coverage and three yearly screening under strategy $A$, the incidence fell to $2 \cdot 00$ and under $B$ to $2 \cdot 10$. The number of smears required was similar but $A$ required two to three times as many colposcopies as $B$. Raising the coverage to $90 \%$ reduced the incidence to around 1 per 10000 per year but changing the screening interval, the specificity or sensitivity of cytology had much less effect. Conclusion-The model has been tested under a wide range of possible variations in natural history, specificity and sensitivity of cytology. For low grade smear abnormalities, open colposcopic referral is predicted to reduce invasive cancer only slightly more than repeat cytology, at the expense of much additional colposcopy. Improving cytological coverage is suggested as more effective in reducing invasive cancer than increased use of colposcopy or more frequent screening.

( Clin Pathol 1994;47:430-435)

Cervical screening is important and costly. About 4.5 million cervical smears are performed by the British National Health Service each year, identifying around 200000 abnormalities that require further investigation. None the less the incidence of cervical cancer remains steady at around $0.02-0.03 \% .{ }^{12}$
Evaluating the overall effectiveness of cervical screening in relation to the contribution of different components is difficult. Determining overall policy requires the evaluation of many possible alternative combinations of cytology, colposcopy, and treatment for their effectiveness in preventing the progression of precancer to invasion and death.

There has been debate, reflected by wide variations of practice, ${ }^{34}$ concerning the relative merits of screening at intervals of less than five years, of achieving more complete coverage of women at risk, and of colposcopy or repeat cytology for low grade smear abnormalities. ${ }^{5-9}$ This has arisen mainly from concern about the limited accuracy of cytology for the detection and grading of tissue changes of precancer and invasive cancer, and uncertainty about the natural history of precancer.

There is detailed information about the effectiveness of colposcopy and the sensitivity and specificity of cervical cytology for detecting cervical abnormality and for predicting its histological grade. ${ }^{10-12}$ There are also areas of uncertainty. High grade precancer (CIN 3) has a high risk of progressing to invasion ${ }^{13}$ but much borderline or mild abnormality detected by smear testing is of low progressive potential, ${ }^{6}$ and sometimes reverts to normal without intervention. ${ }^{714}$ For women with low grade smear abnormalities, however, there is a risk of an underlying high grade precancer, of concurrent unsuspected invasive cancer, or of progression to invasion before the next smear test. $^{315}$ No routine diagnostic method discriminates between lesions of low grade that are likely to progress and those that will not. ${ }^{4}$ Given this diagnostic uncertainty, the management of low grade smear abnormalities, which represent most abnormal smears, is therefore a considerable problem. Concern about the accuracy of cytology in identifying high grade precancer and invasive cancer has led to demands for more frequent screening and for colposcopy for all cytological abnormalities of any grade.

In the management of low grade smear abnormalities, colposcopy offers rapid, accurate diagnosis and effective treatment, but has been criticised as expensive and as distressing to the patient. ${ }^{16}$ Continued follow up remains necessary after treatment. ${ }^{9}$ Monitoring low grade cytological abnormalities by repeat cytology reduces unnecessary treatment, but with some cost in delayed diagnosis of high grade precancer, although the implications for invasive cancer are less clear. ${ }^{7-9}$ 
It is not practical to test every possible combination of screening and management of cytological abnormality in a formal controlled trial. ${ }^{17}$ This paper presents a mathematical technique for estimating the interrelated effects of different policies for cervical screening and for the management of cytological abnormalities. A stochastic model of the progression of precancer at the tissue level has been used to which cytological findings are related. By using a stochastic model it is possible to represent simply the wide range of rates of progression of precancer and the variation in performance of cytology in detecting abnormality.

The model takes into account data relating findings from cytology with histology. It has been designed to examine the relation between the risk of developing invasive cancer and variables such as the numbers of smear tests and colposcopies performed, and the numbers of inappropriate colposcopies. It has been used to investigate the effects of different screening intervals, different levels of coverage of the population, changes in the sensitivity and specificity of cytology, and different rates of progression of precancer.

The model has also been used to evaluate two management strategies for women with low grade cytological abnormalities identified by screening - namely, immediate colposcopic referral or referral only after repeat abnormalities. The impact on invasive cancer and on numbers of investigations are compared for the two policies using the model together with the effects of increasing cytological or colposcopic coverage. This approach provides a new perspective on the integration of the different aspects of the cervical screening programme and on the role of cytology in relation to its limited diagnostic accuracy.

\section{Methods}

The mathematical technique makes use of stochastic modelling ${ }^{18-20}$ to describe the development and progression of premalignancy in a subset of women from a population being screened. Two central features are the assumptions about the progression of precancer and the handling of uncertainties associated with cytology.

Precancer is defined histologically as cervical intraepithelial neoplasia, and graded into three precancerous tissue states: CIN 1, CIN 2 , and CIN 3. The model assumes that untreated patients progress through the different states to invasive cancer (fig 1). Patients who have reached a given tissue state are assumed to have passed through all lower grade states. ${ }^{21} 22$ It is also assumed that CIN 1 can regress, ${ }^{22} 23$ so that a woman may become free of precancer. Progression through these precancer states varies considerably from one

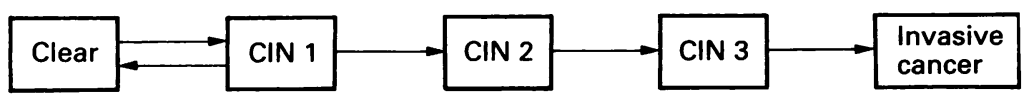

Figure 1 Progression of precancer. woman to another. Some women may rapidly develop CIN 3 and invasive cancer whereas others take many years. Even without treatment, many women never progress beyond CIN 1.

The variability is modelled by assuming that movement between states is a random process. Once a woman has entered a particular precancer state, the time she remains there is assumed to be exponentially distributed. The average time spent in a state will depend on the grade. On leaving one precancer state, one of the transitions shown in fig 1 is made, different transitions being made with different probabilities. The rates of these transitions and their associated probabilities are parameters required by the method and were estimated from available data.

The effectiveness of cytology for determining a woman's tissue state is also modelled with probabilities. Five classes of smear result are assumed: negative, borderline, mild, moderate, and severe, corresponding to the classification of the British Society for Clinical Cytology. ${ }^{24}$ For a woman in a given tissue state all five cytological results are deemed possible. The associated probability of having a result of each type for each tissue grade was estimated from published data. It is assumed that screening is carried out for women in a prespecified age range at regular intervals, unless there is an abnormal smear. If a result is abnormal then the woman has more frequent repeat cytology or receives immediate colposcopy according to the management policy which is modelled. It is assumed that colposcopy, and any subsequent biopsy, allows exact determination of a woman's tissue state and treatment. Successful treatment is modelled as transfer to the clear state. Residual and recurrent precancers are modelled as transfers to other states with specified probabilities. Account is also taken of the proportion who fail to participate in the screening programme, and of age related mortality.

Based on these assumptions it is possible to calculate the probabilities of different outcomes for a population of women offered screening.

This process of analysing the implications of a set of assumptions about a complex system is called mathematical modelling. In the present context, the model derived is stochastic as it makes use of probabilities to represent such features as errors in cytology and the progression of CIN. In principle, a seemingly simpler deterministic model could be proposed whereby, for example, a fixed proportion of smear test results are deemed to be in error. Such a model could not deal adequately with the errors associated with a sequence of smear tests without the introduction of some further assumptions about the interdependence of errors for successive smear tests (the independence of such errors is implicitly assumed in our stochastic model). The use of probability to describe the occurrence of cytology errors, and other elements of the screening process, is not only more plausible, but helps to simplify the analysis. 
Table 1 Percentage of women transferring between tissue states at six months

\begin{tabular}{llcccc}
\hline & \multicolumn{5}{l}{ From } \\
\cline { 2 - 6 } To & Clear & CIN 1 & CIN 2 & CIN 3 & Invasive cancer \\
\hline Clear & $99 \cdot 88$ & 2 & 0 & 0 & 0 \\
CIN 1 & $0 \cdot 12$ & $89 \cdot 5$ & 0 & 0 & 0 \\
CIN 2 & 0 & 6 & 85 & 0 & 0 \\
CIN 3 & 0 & $2 \cdot 5$ & 15 & 99 & 0 \\
Invasive cancer & 0 & 0 & 0 & 1 & 100 \\
\hline
\end{tabular}

Caution must be exercised in interpreting the predictions of such analysis. There is a degree of uncertainty associated with estimating the parameters needed, some of which are not directly available from published clinical trials or from epidemiological studies. In such cases, particularly when formal confidence limits cannot be established, extensive sensitivity analysis was carried out over a wide range of values to test the robustness of the results.

The principal use of the method is for comparing different factors associated with a screening programme, such as the screening interval and the coverage rate, and for comparing the effects of different clinical management strategies.

\section{INPUT DATA}

The estimates of precancer progression rates are based on two studies. ${ }^{23} 25$ The progression of uninvolved tissue to CIN 1 and from CIN 3 to invasive cancer are chosen to reflect the known incidence of invasive cancer. ${ }^{21326}$ The selection of these parameters is not unique and different choices can be made that result in the same predicted incidence of invasive cancer. Table 1 shows the frequencies of transfers between precancer states within six months. It is assumed that no transitions from CIN 1 or 2 to invasive cancer occur during a six month period. In principle, such transitions could occur but with a very small probability. Assigning arbitrary but small probabilities to these transitions makes a negligible difference to the predictions of the model.

For simplicity, we assume that progression is not age related. There is evidence to suggest that progression rates are dependent on age but there are few data on which to calibrate an age related method. The rates in table 1 can be considered as an average rate over all ages for which CIN can be contracted and progress. Given the nature of the data, it is not possible to apply formal confidence limits, but a range of different progression rates have been used during sensitivity analysis,

Table 2 Percentage of women in each tissue state who present with each type of smear

\begin{tabular}{llllll}
\hline \multirow{5}{*}{ Smear result } & Tissue state & & & . \\
\cline { 2 - 6 } & Clear & CIN 1 & CIN 2 & CIN 3 & Invasive cancer \\
\hline Negative & $98(97,98 \cdot 5)$ & $57(70,40)$ & $63(70,40)$ & $0(30,0)$ & 0 \\
Borderline/mild & $1 \cdot 8(2 \cdot 7,1 \cdot 35)$ & $39(27,54)$ & $22(18,36)$ & $50(35,50)$ & 40 \\
Moderate/severe & $0 \cdot 2(0 \cdot 3,0 \cdot 15)$ & $4(3,6)$ & $15(12,24)$ & $50(35,50)$ & 60
\end{tabular}

For the clear tissue state the figures are those under the baseline assumptions (in parentheses, those under the assumptions of low and high specificity of cytology respectively); for the CIN states the figures are those under the baseline assumptions (parentheses, those under the assumptions of low and high sensitivity of cytology respectively). varying from the baseline values by up to $\pm 20 \%$.

Given the smear result, the proportion of women in each tissue state have been taken from published sources. ${ }^{1015}$ From the known relative frequencies of each type of smear, ${ }^{27}$ it is then possible to estimate the proportion of women with each grade of smear given the tissue state. Table 2 shows the results along with the range of values used for sensitivity analysis. The range of values for sensitivity and specificity of cytology have been derived from Giles et al ${ }^{10}$ with the $95 \%$ confidence limits for the proportion of women with clear smears found to have CIN. Death rates by age and life expectancies are taken from published life tables for the years $1980-2 .{ }^{28}$

As a baseline estimate, it is assumed that $70 \%$ of all women between the ages of 21 and 64 attend for regular screening; the remaining $30 \%$ are assumed never to enter the screening programme. Testing was also carried out with coverage rates between $50 \%$ and $90 \%$. $^{5}$

It is assumed that CIN does not develop before the age of 18. Beyond the age of 64 women are assumed no longer able to contract $\mathrm{CIN}$, but existing $\mathrm{CIN}$ can progress to invasive cancer.

The screening interval is assumed to be three years, in accordance with current recommendations; a range of intervals from one year to 10 years was also considered. The probability of successful treatment of precancer after colposcopy is assumed to be $90 \% .^{29}$

Two clinical management strategies based on practices studied previously were compared by means of the model. ${ }^{14}$ Under strategy A, women whose smear tests show any degree of abnormality are immediately referred for colposcopy and treatment. After treatment women have a series of follow up smears at intervals of six months or a year, related to the grade of CIN. If all of these follow up smears are negative women revert to routine screening; any abnormality results in further colposcopy.

Under strategy B women with moderate or severe dyskaryosis are immediately referred for colposcopy. Women with a mild or borderline smear have repeated smears at six monthly intervals. Women whose smear tests are negative for two successive tests revert to routine screening. Women found to have mild, moderate, or severe dyskaryosis on follow up are immediately referred for colposcopy, as are women whose smear tests are persistently borderline. Management after treatment is as under strategy $\mathrm{A}$.

\section{Results}

Given the problems of estimating reliable parameters, the model is intended as a means of assessing the relative effects of changing factors associated with a screening programme, rather than as a precise predictor of incidence of cancer. Its predictions, however, agree closely with published figures for incidence. The model has been calibrated with data from United Kingdom studies. As a check of its validity, the model was used to 
Table 3 Incidence of invasive cancer per 10000 women aged over 20 compared with predictions of the model

\begin{tabular}{llll}
\hline & Finland & Iceland & Latin America \\
\hline Reported incidence & 1.11 & 1.89 & $4 \cdot 75-5 \cdot 82$ \\
Strategy A & 1.22 & $0.73-1.33$ & $5 \cdot 54-6.08$ \\
Strategy B & 1.36 & $0.82-1.40$ & $5 \cdot 56-6.08$
\end{tabular}

Coverage in Latin American districts is assumed to be in the range $0-10 \%$, and in Iceland in the range $80-90 \%$

predict the incidence of cervical cancer in other countries that have different screening policies: Finland and Iceland, where screening has been widespread for many years, and two Latin American districts where little screening takes place. Baseline parameter estimates were used for this purpose. The model's predictions of incidence of cervical cancer were in agreement with published data, ${ }^{30}$ although tending to underestimate incidence for Iceland. Table 3 shows this. Varying the model's parameters in the ranges used for sensitivity analysis gives a range of predictions that encompass the published values in all cases.

The predicted incidence of invasive cancer in an unscreened population of women aged over 18 is 5.9 per 10000 per year. Figure 2 compares the effects of the strategies A (immediate colposcopic referral) and B (cytological follow up) with $70 \%$ coverage. The

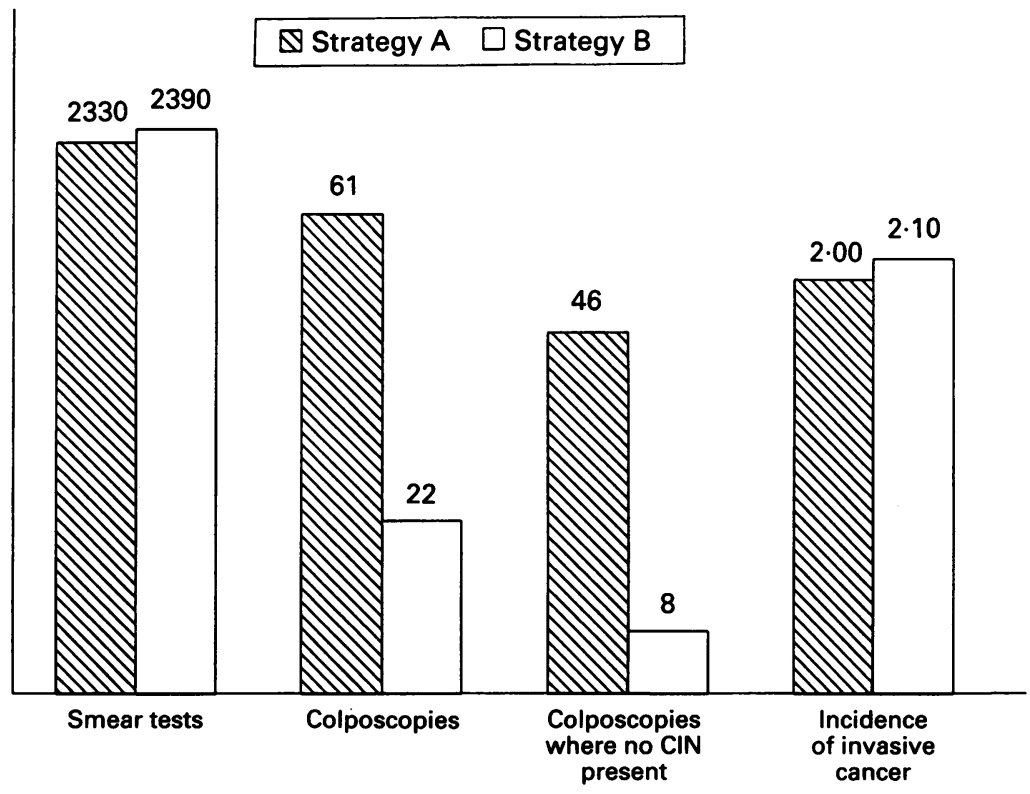

Figure 2 Comparison of screening strategies $A$ and $B$. Number of smear tests and colposcopies per 10000 women aged 18 to 64 per year. Incidence of invasive cancer per 10000 women aged over 18 per year.)

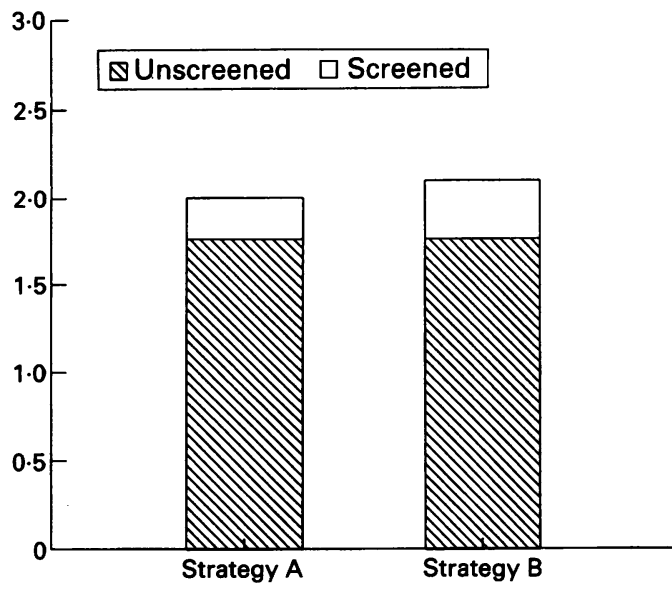

Figure 3 Proportions of invasive cancers from screened and unscreened populations.

incidence of invasive cancer under $A$ and $B$ is 2.0 and 2.1 per 10000 women aged over $18 /$ year respectively. The number of smear tests and colposcopies quoted in fig 2 are per 10000 women aged between 18 and 64 in the screened and unscreened populations together. The total number of smears, under each strategy, are similar, but strategy $A$ leads to nearly three times as many colposcopies and five times as many negative colposcopies as strategy $B$.

Figure 3 shows the relative contributions of the screened and unscreened populations to the total incidence of invasive cancer, under $70 \%$ coverage. The $70 \%$ of the population who are screened are predicted to contribute to between $12 \%$ (strategy A) and $16 \%$ (strategy B) of all invasive cancers. A large majority of invasive cancers are thus contracted by women who have never been screened.

Table 4 summarises the results of using different assumptions of disease progression and the accuracy of cytology. Figure 4 shows the effect of the sensitivity of cytology on the overall incidence of invasive cancer.

A marginal reduction in the incidence of invasive cancer under strategy $A$ at the expense of many more colposcopies is a consistent result for all chosen values of each parameter.

As expected, changing the specificity of cytology has little effect on the incidence of invasive cancer, yet a lower assumption of $97 \%$ compared with $98 \%$ gives rise to a large increase in the number of negative colposcopies.

Table 4 Effects of varying input parameters or incidence of invasive cancer and number of investigations

\begin{tabular}{|c|c|c|c|c|c|}
\hline $\begin{array}{l}\text { Range of parameter } \\
\text { values used }\end{array}$ & & $\begin{array}{l}\text { No of } \\
\text { smear tests* }\end{array}$ & $\begin{array}{l}\text { No of } \\
\text { colposcopies* }\end{array}$ & $\begin{array}{l}\text { Colposcopies } \\
\text { where no } \\
\text { CIN present }\end{array}$ & $\begin{array}{l}\text { Incidence } \\
\text { of invasive } \\
\text { cancert }\end{array}$ \\
\hline $\begin{array}{l}\text { Sensitivity of cytology } \\
\text { Low-high: see table } 2\end{array}$ & $\begin{array}{l}\text { Strategy A } \\
\text { Strategy B }\end{array}$ & $\begin{array}{l}2340-2360 \\
2390-2370\end{array}$ & $\begin{array}{l}60-67 \\
21-23\end{array}$ & $\begin{array}{c}46-47 \\
8-8\end{array}$ & $\begin{array}{l}2 \cdot 20-1 \cdot 94 \\
2 \cdot 38-1 \cdot 99\end{array}$ \\
\hline $\begin{array}{l}\text { Specificity of cytology } \\
\text { Low-high: see table } 2\end{array}$ & $\begin{array}{l}\text { Strategy A } \\
\text { Strategy B }\end{array}$ & $\begin{array}{l}2350-2330 \\
2420-2370\end{array}$ & $\begin{array}{l}85-49 \\
27-20\end{array}$ & $\begin{array}{l}70-34 \\
13-6\end{array}$ & $\begin{array}{l}2 \cdot 00-2 \cdot 01 \\
2 \cdot 10-2 \cdot 10\end{array}$ \\
\hline $\begin{array}{l}\text { CIN progression } \\
-20 \% \text { to }+20 \%\end{array}$ & $\begin{array}{l}\text { Strategy A } \\
\text { Strategy B }\end{array}$ & $\begin{array}{l}2310-2360 \\
2360-2420\end{array}$ & $\begin{array}{l}57-65 \\
18-26\end{array}$ & $\begin{array}{l}46-46 \\
7-9\end{array}$ & $\begin{array}{l}1 \cdot 21-2 \cdot 96 \\
1 \cdot 27-3 \cdot 10\end{array}$ \\
\hline
\end{tabular}

${ }^{\star}$ Numbers of smear tests and colposcopies are per 10000 women eligible for screening per year.

tThe incidence of invasive cancer is per 10000 women aged over 18 per year. 


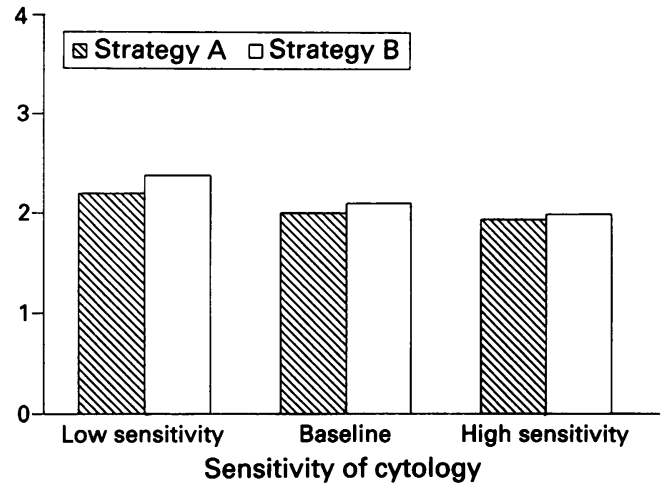

Figure 4 Variation of incidence of invasive cancer by sensitivity of cytology.

Table 5 summarises the results of changing various screening options. Figure 5 illustrates the effects of different routine screening intervals on the incidence of invasive cancer.

The incidence of invasive cancer is most altered by the coverage rate. Raising the coverage to $90 \%$ from $70 \%$ reduces the incidence to around 1 per 10000 per year. Reducing it to $50 \%$ results in an increase in incidence to about $3 \cdot 1$. Achieving $90 \%$ coverage with policy $B$ results in almost as effective a reduction in incidence as with policy A, but with only a small increase in colposcopies.

Changes to the screening interval between routine smear tests produce relatively small changes in incidence of invasive cancer. Reducing the screening interval from three years to one year reduces the incidence of

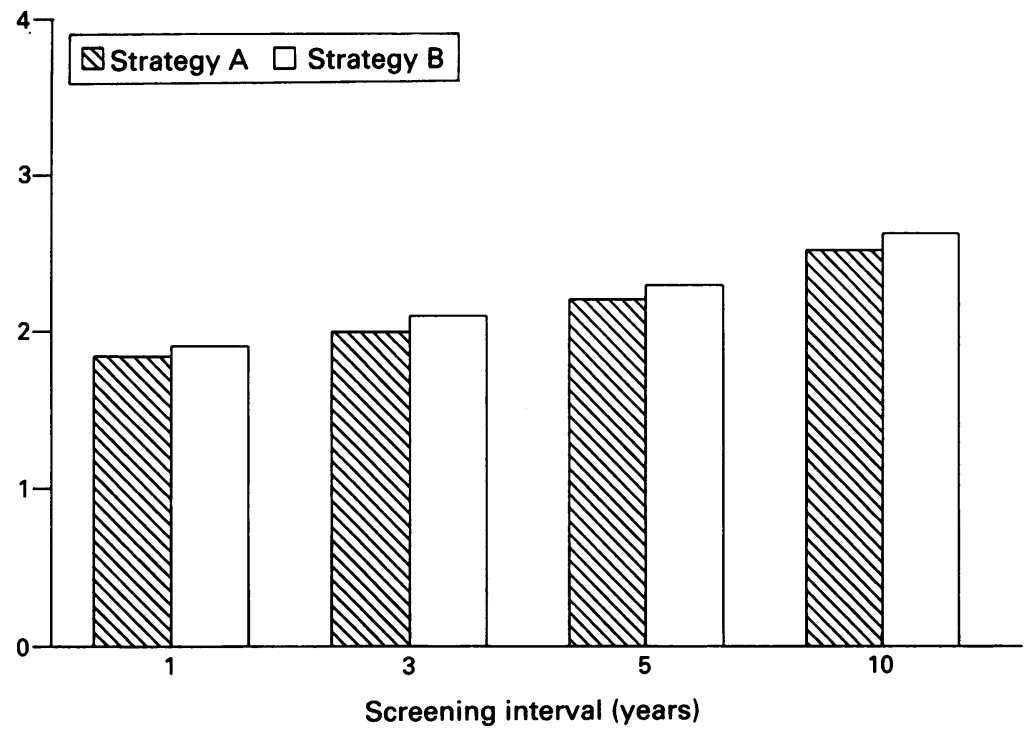

Figure 5 Effect of screening interval on incidence of invasive cancer. invasive cancer from around $2 \cdot 1$ to around 1.9 at the cost of almost trebling the number of smears and doubling the number of colposcopies with an almost threefold increase in negative colposcopies, even when cytological follow up is used (fig 5).

\section{Discussion}

This analysis suggests that in a partially screened population, such as the United Kingdom, the most substantial reduction in the incidence of cervical cancer can be obtained by increasing the proportion of women taking part in the screening programme. Other changes were predicted to have only a minor effect despite the known limited sensitivity of cytology for detecting and grading histological abnormality. For example, open colposcopic referral for all abnormal smears produced a marginal reduction in invasive cancer with an increased and often unnecessary colposcopy when compared with cytological follow up. Changes in the screening interval, particularly in the range one to three years, and in the sensitivity of cytology have a small impact on the incidence of invasive cancer in the whole population. ${ }^{1831}$ Because invasive cancer is predicted to be much more prevalent within the unscreened population, however (fig 3), such changes would have a higher relative impact on those women who participate in the screening programme. This is broadly in line with the findings of the international working group on the evaluation of cancer screening policies, ${ }^{31}$ despite the fact that the methods and data sources are different.

One reason why incidence is insensitive to changes in screening programmes is the slow median progression of $\mathrm{CIN}$ : to progress undetected by regular cytology to invasive cancer, a succession of several false negative smear test results are needed.

The model that has been developed gives an analytical framework for estimating the overall outcome of different screening policies and clinical management strategies. Using outcome measures such as the overall incidence of invasive cancer does not consider the ethical issues faced by a clinician trying to determine the appropriate treatment for a specific woman who has had a mildly abnormal smear test. In principle, analytical methods could assist in such decision making by giving estimates of the probability of progression to invasive cancer. Many other factors would

Table 5 Effects of varying screening options on incidence of invasive cancer and number of investigations

\begin{tabular}{|c|c|c|c|c|c|}
\hline $\begin{array}{l}\text { Range of screening } \\
\text { options used }\end{array}$ & & $\begin{array}{l}\text { No of } \\
\text { smear tests }\end{array}$ & $\begin{array}{l}\text { No of } \\
\text { colposcopies * }\end{array}$ & $\begin{array}{l}\text { Colposcopies } \\
\text { where no } \\
\text { CIN present }\end{array}$ & $\begin{array}{l}\text { Incidence } \\
\text { of invasive } \\
\text { cancert }\end{array}$ \\
\hline $\begin{array}{l}\text { Coverage rates } \\
50 \%-90 \%\end{array}$ & $\begin{array}{l}\text { Strategy A } \\
\text { Strategy B }\end{array}$ & $\begin{array}{l}1670-3000 \\
1710-3070\end{array}$ & $\begin{array}{l}44-79 \\
16-28\end{array}$ & $\begin{array}{r}33-59 \\
6-10\end{array}$ & $\begin{array}{l}3.11-0.90 \\
3 \cdot 18-1.02\end{array}$ \\
\hline $\begin{array}{l}\text { Screening intervals } \\
1 \mathrm{y}-10 \mathrm{y}\end{array}$ & $\begin{array}{l}\text { Strategy A } \\
\text { Strategy B }\end{array}$ & $\begin{array}{l}6580-850 \\
6660-880\end{array}$ & $\begin{array}{r}148-30 \\
34-16\end{array}$ & $\begin{array}{c}131-17 \\
19-4\end{array}$ & $\begin{array}{l}1.85-2.53 \\
1.91-2.64\end{array}$ \\
\hline
\end{tabular}

${ }^{\star}$ Numbers of smear tests and colposcopies are per 10000 women eligible for screening per year.

tThe incidence of invasive cancer is per 10000 women aged over 18 per year. 
need to be taken into account, however, in particular the woman's age. Such issues are beyond the scope of the present discussion.

Mathematical modelling of cervical screening has been discussed in several previous studies. ${ }^{18}{ }^{19}{ }^{32-34}$ Our model is based on a small number of assumptions about the principle features of the precancerous process. The underlying progression of tissue changes cannot be seen directly and has to be inferred from a mixture of cross-sectional and follow up cytological, histological, and colposcopic studies. The assumption of a stochastic progression from normality through three $\mathrm{CIN}$ grades to invasive cancer may be an inaccurate oversimplification ${ }^{2122}$ and the average progression rates assumed are likely to have substantial errors. Given the paucity of data available, more complex models would be difficult to calibrate and would themselves be prone to errors of oversimplification. ${ }^{18} 1932$ Sensitivity analyses covered a wide range of possible alternatives and indicate that the comparison between management policies is insensitive to the rates of progression assumed for CIN. Even if these rates do change with age, or from one group of women to another, similar overall findings would result.

Stochastic modelling, relating biological and clinical information, can provide a quantitative overview of the relative importance of different aspects of complex medical problems. This can supplement conventional clinical epidemiology although it is not a substitute for continuous collection of data or controlled trials. It can inform the debate on alternative clinical management policies under restricted resources and guide the direction of future studies. It can be used to assess the potential of new screening or diagnostic techniques and help to evaluate the impact of quality control of cytological diagnosis and follow up. Such modelling can also be used to investigate alternative hypotheses about the natural history of cervical precancer. ${ }^{35}$

The results of this study provide more evidence that, despite the limited sensitivity of cytology, the main questions about colposcopy or cytological follow up for mildly abnormal smears should concern their cost and acceptability, rather than marginal differences in their effectiveness in preventing invasive cancer within a screening programme. This debate should take second place to improving access and availability of screening.

We are grateful to $\mathrm{Mr}$ A Singer for advice and encouragement. M H Jones was a Jules Thorne Research Fellow of University College and Middlesex School of Medicine at the time of inception of the study. We thank Mrs L Grace for secretaria assistance.

1 Cancer Research Campaign. Fact sheet 13, cervical screening. London: Cancer Research Campaign, 1990.

2 Cancer Research Campaign. Fact sheet 12, cancer of the cervix uteri. London: Cancer Research Campaign, 1990.

cervix uteri. London: Cancer Research Campaign, 1990.
Fletcher A, Metaxas N, Grubb C, Chamberlain J. Four and a half year follow up of women with dyskaryotic cervical smears. $B M \mathcal{F}$ 1990;301:641-4.
4 Woodman CBJ, Jordan JA. Colposcopy services in the West Midlands region. BMF 1989;299:899-901.

5 National Audit Office. Cervical and breast screening in England. London: HMSO, 1992.

6 Smith A, Elkind A, Eardley A. Making cervical screening work. BMF 1989;298:1662-4.

7 Kirby AJ, Spiegelhalter DJ, Day NE, et al. Conservative treatment of mild/moderate cervical dyskaryosis: longterm outcome. Lancet 1992;339:828-31.

8 Soutter WP, Wisdom S, Brough AK, Monaghan JM. Should patients with mild atypia in cervical smear be referred for colposcopy? Br $\mathcal{f}$ Obstet Gynaecol 1986;93: $70-4$.

9 Fox H. Cervical smears: new terminology and new demands. $B M F$ 1987;294:1307-8.

10 Giles JA, Hudson E, Crow J, Williams D, Walker P. Colposcopic assessment of the accuracy of cervical cytology screening. BMF 1988;296:1099-102.

11 Singer A, Walker P, Tay SK, Dyson JL. Impact of introduction of colposcopy to a district general hospital. $B M \mathcal{F}$ 1987;189:1049-54.

12 Tay SK, Jenkins D, Singer A. Management of squamous atypia (borderline nuclear abnormalities): repeat cytology or colposcopy? Aust NZ f Obstet Gynaecol 1987;27: 140-1.

13 McIndoe WA, McLean MA, Jones RW, Mullins PR. The invasive potential of carcinoma in situ of the cervix. Obstet Gynecol 1984;64:451-4.

14 Jones MH, Jenkins D, Cuzick J, et al. Mild cervical dyskaryosis: safety of cytological surveillance. Lancet 1992;339:1440-3.

15 Robertson JH, Woodend BE, Grazier EH, Hutchinson J. Risk of cervical cancer associated with mild dyskaryosis. BMf 1988;297:18-21.

16 Posner T, Vessey M. Prevention of cervical cancer: the patient's view. London: King's Fund, 1988.

17 Jenkins D. Investigations: how to get from guidelines to protocols. BMF 1991;303:323-4.

18 Prorok PC. Mathematical models and natural history in cervical cancer screening. In: Hakama $\mathbf{M}$, Miller $\mathbf{A B}$, Day NE, eds. Screening for cancer of the uterine cervix. Day NE, eds. Screening for cancer of the uterine cervix. 1986:185-93. (IARC sci publ 76.)

19 Boyd A, Davies LA, Bagust A. Modelling the implications for hospital services of cervical cytology screening: A case history. F Operational Research Society 1989;40: 529-37.

20 Cox DR, Miller HD. The theory of stochastic processes. London: Chapman and Hall, 1977.

21 Anderson MC, Brown C, Buckley CH, et al. Current views on cervical intraepithelial neoplasia. f Clin Pathol 1991; 44:969-78.

22 Jenkins $D$. The pathology of lower genital tract premalignancy. Clinical Practice of Gynecology 1991;2:51-85.

23 Richart RM, Barron BA. A follow-up study of patients with cervical dysplasia. Am ₹ Obstet Gynecol 1969;105: with cervic

24 Evans DMD, Hudson EA, Brown CL, et al. Terminology in gynaecological cytopathology: report of the working party of the British Society for Clinical Cytology. $f$ Clin Pathol 1986;39:933-44.

25 Campion MJ, McCance DJ, Cuzick J, Singer A. Progressive potential of mild cervical atypia: prospective cytological, colposcopic and virological study. Lancet 1986;ii: $237-40$.

26 Munoz N, Bosch FX. Epidemiology of cervical cancer. In: Munoz N, Bosch FX, Jensen OM, eds. Human papilloMunoz N, Bosch FX, Jensen OM, eds. Human papillo-
mavirus and cervical cancer. Lyon: International Agency mavirus and cervical cancer. Lyon: International Agency for Research on

27 Department of Health. Form KC53 (adult screening programmes-cervical cytology): 1988/89. DH-SM12B 1991.

28 Johnston E. Office of Population Censuses and Surveys. English life tables No 14. London: HMSO, 1986.

29 Duncan ID (editor). NHS cervical screening programme. Guidelines for clinical practice and programme management. Oxford: National Coordinating Network, 1992.

30 Muir C, Waterhouse J, Mack T, Powell J, Whelan S, eds. Cancer incidence in five continents, Vol 5. Lyon: eds. Cancer incidence in five continents, Vol 5. Lyon: International Agency

31 IARC Working Group on Evaluation of Cervical Cancer Screening Programmes. Screening for squamous cervical cancer: duration of low risk after negative results of cervical cytology and its implications for screening policies. BMf 1986;293:659-64.

32 Coppleson LW, Brown B. Observations on a model of the biology of carcinoma of the cervix: a poor fit between observation and theory. Am F Obstet Gynecol 1975;122: 127-36.

33 Eddy D. Screening for cancer: theory analysis and design. Englewood Cliffs, New Jersey: Prentice-Hall, 1980.

34 Parkin DM. A computer simulation model for the practical planning of cervical cancer screening programmes. $\mathrm{Br} f$ planning of cervical cancer

35 Tidbury P, Singer A, Jenkins D. CIN3: the role of lesion size in invasion. Br f Obstet Gynaecol 1992;99:583-6. 